\title{
PELABELAN TOTAL SISI TAK BERATURAN PADA GRAF GABUNGAN BIPARTIT LENGKAP
}

\author{
Triyani dan Niken Larasati
}

\author{
Fakultas Sains dan Teknik, Universitas Jenderal Soedirman \\ Purwokerto, Indonesia
}

\begin{abstract}
For graph $G=(V, E)$, a labeling $\partial: V(G) \cup E(G) \rightarrow\{1,2, \mathrm{~K}, k\}$ is called an edge irregular total $k$ labeling if for any two different edges e and $f$ of $E(G)$, we have $w(e) \neq w(f)$, where $w(e)=\partial(x)+\partial(e)+\partial(y), \forall x y \in E(G)$. Every graph $G$ with the edge set $E(G) \neq \varnothing$ has an edge irregular total $k$ labeling by labeling all vertex with 1 and the edges with series of number $1,2, \ldots,|E(G)|$. So that the biggest label on graph $G$ is $k=|E(G)|$. Minimum value $k$ in this edge irregular total $k$ labeling called as total irregular edge strength of the graph $G$ notated by tes $(G)$. This research is trying to investigate total irregular edge strength on the union disjoint of complete bipartite graph tes $\left(t K_{m, n}\right)$. The result of the study show that tes $\left(t K_{m, n}\right)$ fulfil the lower bound theorem of $\operatorname{tes}(G)$.
\end{abstract}

Keywords. weight on an edge, total irregular edge strength, edge irregular total $k$ labeling

\section{PENDAHULUAN}

Graf $G$ adalah suatu struktur $(V, E)$ dengan $V(G)$ adalah himpunan tak kosong dengan elemen-elemennya disebut titik dan $E(G)$ (mungkin kosong) adalah himpunan pasangan tak terurut dari titik yang disebut sisi. Misal $e=\{x, y\}$ adalah sisi di $G$, maka $x$ dikatakan tetangga dari $y$ atau sebaliknya. Selanjutnya untuk menyingkat penulisan sisi $e=\{x, y\}$ ditulis $x y$.

Jalan dengan panjang $n$ dari titik $u$ ke titik $v$ adalah barisan titik $\left(x=x_{0}, x_{l}\right.$, $x_{2}, \ldots, x_{n-1}, x_{n}=y$ ) demikian sehingga $x_{i-1} x_{i} \in E(G)$, untuk setiap $i$. Lintasan adalah jalan yang semua titiknya berbeda. Graf $G$ dikatakan terhubung jika untuk setiap dua titik berbeda di $G$ terdapat lintasan yang menghubungkan kedua titik tersebut. Jika tidak ada lintasan yang menghubungkan setiap dua titik yang berbeda di $G$, maka graf $G$ dikatakan tidak terhubung. 
Pelabelan dari graf $G$ adalah suatu pemetaan yang memetakan unsur-unsur graf ke bilangan (umumnya bilangan bulat non negatif atau positif) yang disebut label (Gallian, 2003). Pada umumnya domain dari pemetaan ini adalah himpunan titik (selanjutnya disebut pelabelan titik), himpunan sisi (disebut pelabelan sisi) atau himpunan titik dan himpunan sisi (disebut pelabelan total). Jumlah semua label yang dikaitkan dengan unsur suatu graf disebut dengan bobot dari unsur tersebut.

Suatu pelabelan dikatakan pelabelan $k$ total sisi tak beraturan jika terdapat suatu pemetaan dari titik dan sisi di graf $G$ ke himpunan bilangan asli demikian sehingga untuk setiap dua sisi $e \operatorname{dan} f$ di $G$, berlaku $w(e) \neq w(f)$ dengan $w(e)$ dan $w(f)$ berturut-turut menyatakan bobot total sisi $e$ dan bobot total sisi $f$. Bobot total sisi $e$ terhadap pelabelan $\partial$ didefinisikan sebagai

$$
w(e)=\partial(x)+\partial(e)+\partial(y), \quad \forall e=x y \in E(G) .
$$

Setiap graf yang mempunyai sisi dapat dilabeli dengan pelabelan total sisi tak beraturan dengan cara melabeli semua titiknya dengan bilangan 1 dan sisi-sisinya dengan bilangan terurut mulai dari $1,2, \ldots,|E(G)|$. Pelabelan total sisi tak beraturan dari graf $G$ yang diperoleh mempunyai label terbesar $k=|E(G)|$.

Permasalahannya adalah bagaimana menentukan nilai minimum $k$ dari graf $G$, sehingga graf $G$ dapat dilabeli dengan pelabelan $k$ total sisi tak beraturan. Nilai minimum $k$ untuk pelabelan $k$ total sisi tak beraturan dari graf $G$ disebut kekuatan total sisi tak beraturan (total edge irregular stength) yang dinotasikan dengan tes $(G)$. Selanjutnya, tujuan penelitian adalah menentukan nilai kekuatan total sisi tak beraturan dari graf gabungan bipartit lengkap, tes $\left(t K_{m, n}\right)$.

\section{HASIL DAN PEMBAHASAN}

Ada beberapa acuan yang digunakan untuk menentukan nilai tes $(G)$. Baca et. al (2007) memberikan batas bawah dan batas atas dari nilai kekuatan total sisi tak beraturan. 
Teorema 1. Jika $G=(V, E)$ graf dengan himpunan titik tak kosong $V(G)$ dan himpunan sisi $E(G)$, maka

$$
\frac{|E(G)|+2}{3} \leq \operatorname{tes}(G) \leq|E(G)|
$$

Bukti. Untuk membuktikan batas atas tes $(G)$, definisikan pelabelan total $\partial$, pilih $\partial(x)=1$, untuk setiap $x \in V(G)$. Labeli semua sisi di $G$ secara berurutan dengan 1, $\ldots,|E(G)|$. Akibatnya, bobot setiap dua sisi e dan $\mathrm{f}$ di $\mathrm{G}$ berbeda, yaitu $w(e) \neq w(f)$ dan label terbesar adalah $|E(G)|$. Untuk membuktikan batas bawah tes $(G)$, definisikan bobot sisi terhadap pelabelan total $\partial, w(e)=\partial(x)+\partial(e)+\partial(y)$ dengan $e=x y$ sisi di $G$. Bobot terbesar sisi e di $E(G)$, adalah $w(e) \geq|E(G)|+2$. Perhatikan bahwa

$$
\begin{aligned}
\operatorname{tes}(G) & \geq \operatorname{maks}\{\partial(u), \partial(e), \partial(v)\} \\
& \geq \frac{\partial(u)+\partial(e)+\partial(v)}{3}=\frac{w(e)}{3} \geq \frac{\mid E(G)+2}{3} .
\end{aligned}
$$

Jadi,

$$
\frac{|E(G)|+2}{3} \leq \operatorname{tes}(G) \leq|E(G)| .
$$

Baca et. al (2007) juga telah membuktikan tes $(G)$, untuk $G$ adalah graf lintasan $\left(P_{n}\right)$, graf lingkaran $\left(C_{n}\right)$, graf lengkap $\left(K_{p}\right)$ untuk $2 \leq p \leq 5$ dan graf roda $\left(W_{n}\right)$. Hasil-hasil ini dituangkan dalam teorema berikut

Teorema 2. Misal $P_{n}$ dan $C_{n}$ masing-masing adalah graf lintasan dan graf lingkaran, dengan $n \geq 1$ maka

$$
\operatorname{tes}\left(P_{n}\right)=\operatorname{tes}\left(C_{n}\right)=\left\lceil\frac{n+2}{3}\right\rceil \text {. }
$$

Teorema 3. Misal $S_{n}=K_{1, n}$ adalah graf bintang dengan $n+1$ titik. Untuk suatu

$$
n>1 \text { maka tes }\left(S_{n}\right)=\left\lceil\frac{n+1}{2}\right\rceil \text {. }
$$


Teorema 4. Misal Graf $G=(V, E)$ dengan $|V(G)|=p$ maka tes $(G) \leq t e s\left(K_{p}\right)$.

Kekuatan total sisi tak beraturan pada graf lengkap, tes $\left(K_{p}\right)$, untuk $p \geq 6$ telah yang dibuktikan oleh Triyani (2002). Begitu juga tes $\left(m K_{p}\right)$ dengan $m K_{p}$ adalah graf gabungan terpisah dari graf lengkap sebanyak $m$ komponen. Selanjutnya Nurdin d.k.k. (2005) mengkaji tes $\left(s L_{n}\right)$ dengan $s L_{n}$ adalah graf gabungan terpisah dari graf lintang. Hasil-hasil ini dituangkan dalam teorema berikut:

Teorema 5 (Triyani, 2002). Jika $K_{p}$ adalah graf lengkap dengan p titik, maka

$$
\operatorname{tes}\left(K_{p}\right)=\left\lceil\frac{p^{2}-p+4}{6}\right\rceil, \text { untuk } p \geq 6 .
$$

Teorema 6 (Triyani, 2002). Jika $m K_{p}$ adalah graf gabungan terpisah dari graf lengkap $K_{p}$, untuk $\mathrm{p} \geq 6$, maka

1. Jika $\mathrm{p} \equiv 0 \bmod 3$ dan $\mathrm{p} \equiv 1 \bmod 3, \operatorname{maka} \operatorname{tes}\left(m K_{p}\right)=\frac{p(p-1)}{6} m+1$,

2. Jika $\mathrm{p} \equiv 2 \bmod 3, \operatorname{maka} \operatorname{tes}\left(m K_{p}\right)=\frac{p(p-1) m+4}{6}$.

Teorema 7 (Nurdin dkk, 2005). Untuk suatu bilangan bulat positif $s \geq 1$ dan $n \geq 2$ berlaku

$$
\operatorname{tes}(s L n)=\left\lceil\frac{2 n s+2}{3}\right\rceil
$$

Teorema berikut merupakan hasil investigasi dari nilai kekuatan total sisi tak beraturan pada graf gabungan lengkap bipartit, $\operatorname{tes}\left(t K_{m, n}\right)$.

Teorema 8. Jika $t K_{m, n}$ adalah graf gabungan terpisah bipartit lengkap dengan

$$
2 \leq m \leq n, \text { maka tes }\left(t K_{m, n}\right)=\left\lceil\frac{m n t+2}{3}\right\rceil .
$$




\section{Bukti:}

Misal himpunan titik dan sisi pada gabungan terpisah graf bipartit lengkap $t K_{m, n}$ didefinisikan sebagai:

$$
\begin{aligned}
& V\left(t K_{m, n}\right)=\left\{v_{i}^{s} \mid 1 \leq i \leq m, 1 \leq s \leq t\right\} \cup\left\{w_{j}^{s} \mid 1 \leq j \leq n, 1 \leq s \leq t\right\}, \\
& E\left(t K_{m, n}\right)=\left\{v_{i}^{s} w_{j}^{s} \mid 1 \leq i \leq m, 1 \leq j \leq n, 1 \leq s \leq t\right\} .
\end{aligned}
$$

Karena $\left|E\left(t K_{m, n}\right)\right|=m n t$, maka berdasarkan teorema 1 diperoleh

$$
\operatorname{tes}\left(t K_{m, n}\right) \geq\left\lceil\frac{m n t+2}{3}\right\rceil
$$

Selanjutnya, untuk membuktikan $\operatorname{tes}\left(t K_{m, n}\right) \leq\left\lceil\frac{m n t+2}{3}\right\rceil$, terlebih dahulu labeli titik-titik dan sisi-sisi pada graf gabungan terpisah dari graf bipartit lengkap. Pertama definisikan $r$ suatu bilangan bulat positif yang menyatakan banyaknya label 1 pada titik di graf $t K_{m, n}$, dengan

$$
r=\left\{\begin{array}{c}
\frac{2}{3} m-1, \text { jika } m \equiv 0 \bmod 3 \\
\frac{2 m-2}{3}, \text { jika } m \equiv 1 \bmod 3 \\
\frac{2 m-1}{3}, j i k a m \equiv 2 \bmod 3
\end{array}\right.
$$

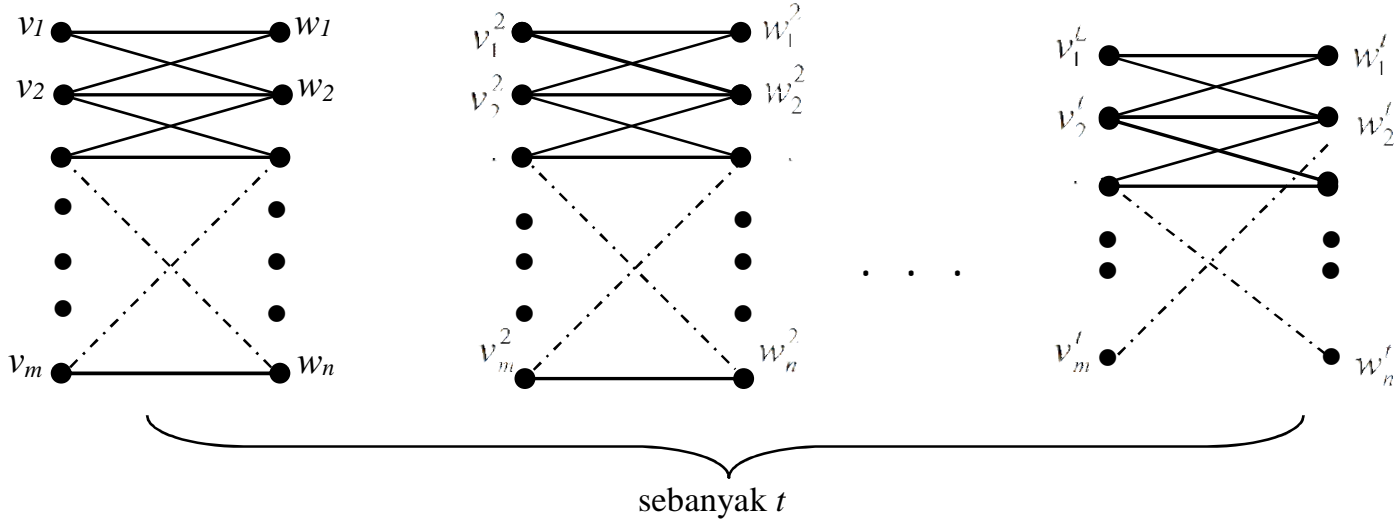

Gambar 1. Graf Gabungan Bipartit lengkap $t K_{m, n}$ 
Terdapat 3 kasus, untuk melabeli titik dan sisi pada graf gabungan bipartit lengkap, yaitu kasus $m \equiv 0 \bmod 3, m \equiv 1 \bmod 3$ dan $m \equiv 0 \bmod 3$. Pada paper ini hanya akan diuraikan untuk kasus $m \equiv 0$ mod3. Jika $\partial$ menyatakan pelabelan total sisi tak beraturan pada graf gabungan bipartit lengkap, maka label untuk titiktitik dan sisi-sisi graf gabungan bipartit lengkap $t K_{m, n}$ dengan $\mathrm{m} \equiv 0 \bmod 3$ adalah sebagai berikut.

\section{Label titik}

$$
\begin{aligned}
& \partial\left(v_{i}^{s}\right)= \begin{cases}\frac{m n(s-1)+3}{3}, & 1 \leq i \leq r \\
\left\lceil\frac{m n s+2}{3}\right\rceil, & r+1 \leq i \leq m\end{cases} \\
& \partial\left(w_{j}^{s}\right)= \begin{cases}\frac{m n(s-1)+3}{3}, & j=1 \\
\frac{m n(s-1)+m j}{3}, & 2 \leq j \leq n\end{cases}
\end{aligned}
$$

untuk setiap $i=1,2, \ldots . ., m ; j=1,2, \ldots . ., n$ dan $s=1,2, \ldots . ., t$

\section{Label sisi.}

Jika $v_{i}^{s} w_{j}^{s}$ menyatakan sisi pada komponen graf ke-s yang merupakan pasangan titik $v_{i}$ dan $w_{j}$, maka label sisi-sisi di graf $t K_{m, n}$ adalah

$$
\partial\left(v_{i}^{s} w_{j}^{s}\right)= \begin{cases}r j+i-r+m n(s-1)+2-\partial\left(v_{i}^{t}\right)-\partial\left(w_{j}^{t}\right) & , 1 \leq i \leq r \\ (m-r) j+r n+i-m+m n(s-1)+2-\partial\left(v_{i}^{t}\right)-\partial\left(w_{j}^{t}\right), r+1 \leq i \leq m\end{cases}
$$

untuk setiap $j=1,2, \ldots ., n$ dan $s=1,2, \ldots ., t$. Selanjutnya ditunjukkan bahwa label terbesar pada titik atau sisi adalah kurang dari atau sama dengan $\left\lceil\frac{m n t+2}{3}\right\rceil$. 


\section{Label terbesar titik.}

Label terbesar untuk titik $v_{i}^{s}$ dengan $i=1,2, \ldots . ., m ; s=1,2, \ldots ., t$ diperoleh pada saat $i=m$ dan $s=t$, yaitu $\partial\left(v_{i}^{s}\right)=\left\lceil\frac{m n t+2}{3}\right\rceil$.

Label terbesar untuk titik $w_{j}^{s}$ dengan $j=1,2, \ldots ., n ; s=1,2, \ldots . ., t$ diperoleh pada saat $j=n$ dan $s=t$, yaitu

$$
\partial\left(w_{j}^{s}\right)=\frac{m n(t-1)+m n}{3}=\frac{m n t-m n+m n}{3}=\frac{m n t}{3}<\frac{m n t+2}{3} \leq\left\lceil\frac{m n t+2}{3}\right\rceil .
$$

\section{Label terbesar sisi}

Label terbesar untuk sisi $v_{i}^{s} w_{j}^{s}$ dengan $i=1,2, \ldots ., m ; j=1,2, \ldots ., n$ dan $s=1,2, \ldots . ., t$ diperoleh pada saat $i=m ; j=n$ dan $s=t$, yaitu

$$
\begin{aligned}
& \partial\left(v_{i}^{s} w_{j}^{s}\right)=\left(m-\left(\frac{2}{3} m-1\right)\right) n+\left(\frac{2}{3} m-1\right) n+m-m+m n(t-1)+2-\left\lceil\frac{m n t+2}{3}\right\rceil \\
& -\frac{m n(t-1)+m n}{3} \\
& =m n-\left(\frac{2}{3} m-1\right) n+\left(\frac{2}{3} m-1\right) n+m n t-m n+2-\left\lceil\frac{m n t+2}{3}\right\rceil \\
& -\frac{m n t-m n+m n}{3} \\
& =m n t+2-\left\lceil\frac{m n t+2}{3}\right\rceil-\frac{m n t}{3} \\
& =3\left(\frac{m n t+2}{3}\right)-\left\lceil\frac{m n t+2}{3}\right\rceil-\frac{m n t}{3} \\
& =\frac{3 m n t+6}{3}-\left\lceil\frac{m n t+2}{3}\right\rceil-\frac{m n t}{3} \\
& =\frac{2 m n t+6}{3}-\left\lceil\frac{m n t+2}{3}\right\rceil \\
& =\frac{2 m n t+6}{3}-\frac{m n t+3}{3} \text {. } \\
& =\frac{m n t+3}{3}=\left\lceil\frac{m n t+2}{3}\right\rceil \text {. }
\end{aligned}
$$


Selanjutnya, perhatikan bahwa bobot total sisi terhadap pelabelan $\partial$ adalah

$$
\begin{aligned}
w\left(v_{i}{ }^{s} w_{j}{ }^{s}\right) & =\partial\left(v_{i}^{s}\right)+\partial\left(v_{i}^{s} w_{j}^{s}\right)+\partial\left(w_{j}^{s}\right) . \\
& =\left\{\begin{array}{c}
r j+i-r+m n(s-1)+2, \quad 1 \leq i \leq r \\
(m-r) j+r n+i-m+m n(s-1)+2, r+1 \leq i \leq m
\end{array}\right.
\end{aligned}
$$

dengan $i \in\{1,2, \ldots ., m\}$ dan $j \in\{1,2, \ldots ., n\}$.

Untuk suatu $j \in\{1,2, \ldots ., n\}$, jelas bahwa $\omega\left(v_{i}^{s} w_{j}^{s}\right) \neq \omega\left(v_{i}^{s} w_{j}^{s}\right)$ dengan $i \neq i$ $\in\{1,2, \ldots ., m\}$.

Untuk suatu $i \in\{1,2, \ldots . ., m\}$, jelas bahwa $\omega\left(v_{i}^{s} w_{j}^{s}\right) \neq \omega\left(v_{i}^{s} w_{j^{\prime}}^{s}\right)$ dengan $j \neq j^{\prime}$ $j \in\{1,2, \ldots ., n\}$.

\section{KESIMPULAN DAN SARAN.}

Hasil penelitian diperoleh nilai kekuatan total sisi tak beraturan pada graf gabungan bipartit lengkap memenuhi batas bawah teorema tes $(G)$, yaitu $\operatorname{tes}\left(t K_{m, n}\right)=\left\lceil\frac{m n t+2}{3}\right\rceil$, untuk $2 \leq m \leq n$.

Saran untuk penelitian lebih lanjut adalah investigasi nilai kekuatan total sisi tak beraturan pada graf tripartit, graf multipartit dan graf-graf gabungannya.

\section{DAFTAR PUSTAKA}

Baca, M. S., Jendrol, Miller, M. dan Ryan, J., On Irregular Total Labelings, Discrete Mathematics, Vol. 307 page: 1378-1388, 2007.

Gallian, J.A., A Dynamic Survey of Graph Labeling, Department of Mathematics and Statistics University of Minnesota, Duluth, 2003.

Nurdin, Baskoro, E.T., dan Salman, A.N.M., Total Edge Irregular Strength, Seminar MIPA, UI, 2005.

Triyani, Hasil Baru pada Pelabelan Total Sisi Tak Beraturan, Tesis, ITB, 2002. 